\title{
Nitrate and oxalate in germplasm collections of spinach and other leafy vegetables
}

\author{
Svein O. Solberg ${ }^{1 *}$, Flemming Yndgaard ${ }^{1}$, Johan Axelsson ${ }^{1}$ \\ ${ }^{1}$ Nordic Genetic Resource Center, Box 41, 23053 Alnarp, Sweden
}

\section{A B S T R A C T}

\begin{abstract}
Accumulation of nitrate and oxalate is a concern in the production and marketing of leafy vegetables. High nitrate levels can be related to fertilization regime, light conditions and plant factors. Plant factors are of major importance for oxalate content. Plant breeding has been reported as one way of reducing the content of nitrate and oxalate. In this study we have examined germplasm collections of spinach (Spinacia oleracea), orache (Atriplex hortensis) and rocket (Eruca sativa). For spinach contents were related to morphological characters and to breeding method. Across accessions, rocket showed significantly higher nitrate levels than spinach and orache. No clear differences were detected between spinach and orache with regard to either nitrate or oxalate content. However, oarche showed higher dry matter content. A general strong positive correlation was found between nitrate and oxalate. The mechanism behind such a relationship is discussed but not fully understood. No differences were detected between old and new spinach cultivars or between open-pollinated cultivars and F1-hybrids, but potential interesting accessions for future breeding of low-nitrate/low-oxalate spinach were identified.
\end{abstract}

Keywords: Breeding; Eruca sativa; Orache; Rocket; Spinacia oleracea

\section{INTRODUCTION}

Spinach (Spinacia oleracea) is an important vegetable worldwide with one million hectares cultivated annually (FAOSTAT 2013). The production and consumption have doubled the last decade. Spinach is considered to be an important source of vitamins $\mathrm{C}$ and $\mathrm{A}$, carotenoids, flavonoids, folic acid, calcium and magnesium (Koh et al., 2012). On the other hand, the content of nitrate and oxalate can be high, which can be a concern to human health. Nitrate can be converted into nitrite, which can react with amines and amides to produce $\mathrm{N}$-nitroso compounds (Yordanov et al., 2001; Santamaria, 2006, Zeilmaker et al., 2010). Oxalate can react with calcium and other minerals, forming crystals which then inhibit mineral absorption (Noonan and Savage, 1999; Bohn et al., 2004). High nitrate levels are frequently found in vegetables from the Brassicaceae, such as rocket and radish, Chenopodiaceae, including plants such as beet root and spinach, but also in Asteraceae (lettuce) and Apiaceae (celery and parsley) (Santamaria et al., 1999; Ghidurus et al., 2012; Qiu et al., 2014). High oxalate concentration is most commonly found in vegetables from the Chenopodiaceae, but also Polygonaceae
(Kameno et al., 1990; Ota and Kagawa, 1996). European Commission Regulation No. 563/2002 sets limits for maximum nitrate content in vegetables. For spinach this is 2000-3000 $\mathrm{mg} \mathrm{NO}_{3} \mathrm{~kg}^{-1}$ fresh weight (depending on the conservation method and fresh market season), and for lettuce 2000-4500 $\mathrm{mg} \mathrm{NO}_{3} \mathrm{~kg}^{-1}$ fresh weight (depending on crop type and cultivation method) (Santamaria, 2006). Rocket is not in the regulation, but Germany and Switzerland permit a maximum of 2400-4000 $\mathrm{mg} \mathrm{NO}_{3} \mathrm{~kg}^{-1}$ fresh weight for rocket. For oxalate there is no regulation.

The food industry needs to find ways to produce vegetables with low levels of nitrate and oxalate. High nitrate concentration in plants is related to the nitrogen fertilization regime (Palaniswamy, 2003; Okazaki et al., 2006; Stagnari et al., 2007; Krężel and Kołota, 2014; Chan-Navarrete et al., 2014; Croitorua et al., 2015). Pre-harvest light intensity is also of importance (Proietti et al., 2004; Kosma et al., 2013). Seasonal variation is observed (Kaminishi and Kita, 2006; Kosma et al., 2013; Lester et al., 2013). Plant factors is also of importance, with the highest nitrate levels often detected in the petiole, followed by the leaves and roots (Wang et al., 2006). Nitrate concentration is known to decrease with

\footnotetext{
${ }^{*}$ Corresponding author:

Svein O. Solberg, Svein O. Solberg, Scenior scientist, Nordic Genetic Resource Center, Box 41, 23053 Alnarp, Sweden.

E-mail: sveinsolberg63@gmail.com
} 
plant age (Kameno et al., 1990). Concentration of oxalate is often highest in the plant's oldest leaves (Kameno et al., 1990; Okutani and Sugiyama, 1994). However, different results have been reported (Palaniswamy, 2003). For nitrate there are some old studies that examine the content in cultivars and germplasm collections (Lorenz 1978; Shen et al. 1986; Groenword 1988) and a few more recent ones (Mou, 2008; Koh et al., 2012; Krężel and Kołota, 2014; Qiu et al., 2014). In contrast to nitrate, the deposition of oxalate is localized mostly in leaf blades (Kawazu et al., 2003; Stagnari et al., 2007). Some differences have been found among cultivars but collections are not well studied (Okutani and Sugiyama, 1994; Kawazu et al., 2003).

Plant breeding is one way to deal with unwanted compounds in plants. Denmark and Sweden have had an important spinach breeding. The first commercial cultivars were released in the 1927 and most of the cultivars are maintained in the germplasm collection at the Nordic Genetic Resource Center (NordGen). This collection was characterized and evaluated with the aim to to identify accessions for low nitrate and oxalate content and to describe the associations between nitrate, oxalate and morphological characters of the plants. If low content cultivars could be detected, such cultivars could be interesting to re-introduce to the market or they could be used in future breeding programs. Orache (Atriplex hortensis) is an alternative leafy vegetable that is traditionally used as spinach and that are thought to potentially have low nitrate or oxalate levels. No research has been possible to find on the content in orache and therefore this crop was included in the study. Rocket (Eruca sativa) is a leafy vegetable that is becoming more important in the fresh market, and was included for a comparison.

\section{MATERIAL AND METHODS}

\section{Plant material}

The spinach material includes 41 accessions, all bred in the Nordic countries and stored in the genebank at NordGen (SESTO, 2015). The studied orache includes 15 accessions from the same collection, all locally-cultivated material or landraces collected from old gardens in Sweden and Denmark (Table 1). The rocket material includes 20 accessions from the German gene bank but with a worldwide origin (IPK, 2015).

Plants were cultivated at Alnarp, Sweden $\left(55^{\circ} \mathrm{N}, 13^{\circ} \mathrm{E}\right)$, grown in $2 \frac{1}{2} 1$ pots with a mixed fertilized soil with $70 \%$ organic matter (P-jord ${ }^{\text {TM }}$ from Hasselfors, Norway) and with a content of $240 \mathrm{mg}$ available nitrogen $\mathrm{L}^{-1}$ and a proper balance of other nutrients (70 mg P, $250 \mathrm{mg} \mathrm{K,} 350 \mathrm{mg} \mathrm{Ca}$, $\left.200 \mathrm{mg} \mathrm{Mg} \mathrm{L}^{-1}\right)$. Each accession consisted of five pots with three plants each (15 plants in total). Pots were placed
Table 1: Overview of plant material included in the study with a short code, the accession number and the accession name Spinach (Spinacia oleracea) 1=NGB2022DOMINANT, 2=NGB2023 FREJA, 3=NGB2024 FØRSTE SNIT DISKANT, 4=NGB2025 FØRSTE SNIT FORMI, 5=NGB2026 KONGEN AF DANMARK AMBASSADEUR, 6=NGB2027 KONGEN AF DANMARK DURAN, 7=NGB2028 KONGEN AF DANMARK KONSAN, 8=NGB 2030 MATADOR FANFARE, 9=NGB2031, MATADOR MATARNO, 10=NGB2032 MATADOR NOBIO, 11=NGB2033 MERKUR, 12=NGB2034 MEDANIA, 13=NGB2035 MÜNSTER-LÄNDER RUNDFRØET, 14=NGB2036 MÜNSTERLÄNDER SPIDSFRØET, 15=NGB2037 ROLAND, 16=NGB2038 SELANDIA TONI, 17=NGB2040 VINTER RIESEN WIRI, 18=NGB2041 VIROFLAY NIKE, 19=NGB2042 VIROFLAY OVINTA, 20=NGB2043 BLOOMSDALE BLOMARA, 21=NGB2044 NOBEL TAGENSHUS, 22=NGB2045 MATADOR, 23=NGB2047 KONGEN AF DENMARK A HUNDERUP, 24=NGB2406 VIKIN A HUNDERUP, 25=NGB2425 VIROFLAY 229, 26=NGB7762 UNIVERSAL UNVER, 27=NGB11703 REBRIS, 28=NGB11951 HECTOR, 29=NGB1195 HYDANE F1, 30=NGB11955 FIRNO, 31=NGB11961 SELANDIA SELO, 32=NGB11962 BLONGO, 33=NGB12137 MATADOR "NOBIO", 34=NGB12138 MATADOR "MATARNO", 35=NGB12139 KONGEN AF DANMARK "KONSAN", 36=NGB13633 HEBE F1, 37=NGB13947 KUNGEN AV DANMARK, 38=NGB13957 VERINA, 39=NGB13960 HAMMENHÖGS VINTER, 40=NGB15900 FORDANE F1, 41=NGB15905 UNIDANE F1

Orache (Atriplex hortensis)

38=NGB17924 REFTELE TRÄDGÅRDSMÅLLA, 39=NGB 20144 HASLEV FAKSE HAVEM/ELDE, 40=NGB14282 28-G 41=NGB14284 31-G, 42=NGB20130 LILLE NAESTVED SKOLE, 43=NGB20143 MOSTER KARENS SPINAT, 44=NGB2379 TRÄDGÅRDSMÅLLA, 45=NGB11726 TRÄDGÅRDSMÅLLA, 46=NGB20087 HAVEM/ELDE GRøN, 47=NGB11755

TRÄDGÅRSDMÅLLA, 48=NGB11754 TRÄDGÅRDSMÅLLA, 49=NGB17923 NISSES TRÄDGÅRDSMÅLLA, 50=NGB17948 JAPANSK SPENAT, 51=NGB17954 TRÄDGÅRDSMÅLLA FRÅN LÖNNEBERGA, 52=NGB18058 MORMORS SPENAT

Rocket (Eruca sativa)

ERU94 (from Pakistan), ERU34 (from Italy), ERU13 (from Egypt), ERU107 (from Pakistan), ERU143 (from USSR ${ }^{a}$ ), ERU26 (from Croatia), ERU21 (from Yugoslaviaa),

ERU19 (from Italy), ERU14 (from Italy), ERU153 (from USA), ERU30 (from Spain), ERU23 (from Libya), ERU18 (from Italy), ERU28 (from China), ERU29 (from Italy), ERU140 (from Turkey), ERU17 (from Italy), ERU154 (from Czechoslovakiaa), ERU158 (from Portugal), ERU12 (from Iran)

ald names of these countries are used because the accessions were collected at that time

outdoor on Mypex and irrigated daily. Spinach and rocket were sown in August due to risk of bolting, and orache was sawn in April as commonly done for this crop. Samples for chemical analysis were harvested 38-45 days after sowing, at a stage when the biggest leaves reached 10-12 cm (38 days for spinach and rocket, 45 days for orache). Leaves from at least ten plants were harvested, sealed in plastic bags and frozen prior to analysis.

\section{Chemical analysis}

Nitrate and oxalate analyses were carried out using High-performance liquid chromatography at Svenska Cereallaboratoriet (Svalöv, Sweden). The content was given in $\mathrm{mg} 100 \mathrm{~g}^{-1}$ fresh weight, and converted into $\mathrm{mg} \mathrm{kg}^{-1}$. Dry matter content was also measured at the same laboratory. 
The results were given as a mean of two measurements per sample.

\section{Morphological characterization}

The spinach accessions were also described according a descriptor list including: seed spines (SeeSpi, $0=$ absent, $1=$ present $)$, stem anthocyanin content (Stem_Anth, scale 0-7 from absent to very strong), leaf shape excluding basal lobes (Leaf_shape, $1=$ elliptic, $2=$ broad elliptic, $3=$ circular, $4=$ ovate, $5=$ broad ovate, $6=$ irregular), leaf colour (Leaf_Col, 1=yellow-green, 2=grey-green, 3=dark-green), leaf colour intensity (Leaf_col_int, $3=$ light, $5=$ medium, $7=$ dark), leaf blistering (Leaf_blis, $3=$ weak, $5=$ medium, $7=$ strong), all scored at the $7^{\text {th }}$ leaf stage. The results were given as a mean of two readings per accession and cultivated on two separate plots. Intermediate values could therefore be established. Bolting time (Bolt, number of days from sowing until 15\% of the plants have a $5 \mathrm{~cm}$ long stem) and monoecious plants (Monoe, in \%) were examined at the end of the growing season. The work was done under field cultivation at University of Aarhus, Department of Horticulture, Denmark $\left(55^{\circ} \mathrm{N} 10^{\circ} \mathrm{E}\right)$. Orache and rocket accessions were not described by morphology.

\section{Statistical analysis}

Analyses were carried out by applying $\mathrm{R}$ software ( $\mathrm{R}$ Core Team, 2014). Standard ANOVA tests (in $\mathrm{R}$ the function aov) and Tukey's 'Honest Significant Difference methods were used to identify significant differences in means values between spinach, orache and rocket. For spinach, the $\mathrm{R}$ function heatmap was used to demonstrate dendrograms for both accessions and variables in the same picture; dissimilarities are expressed as different colours. This is a two-way cluster analysis. A Pearson correlation matrix (scatterplot in R) was set up to further analyse the relationship among descriptors. A bivariate boxplot method was also applied. This type of boxplot is useful for revealing correlation as well as any outliers. It consists of two concentric ellipses, one of which (the "hince") includes $50 \%$ of the data while the other (the "fence") delineates potential outliers. Furthermore, regression lines of both $\mathrm{y}$ on $\mathrm{x}$ and $\mathrm{x}$ on $\mathrm{y}$ are shown, with intersection indicating the bivariate location of the estimator. The size of the angle between the regression lines indicates the correlation (Everitt and Hothorn, 2011). Information on the release year of the cultivars was used to illustrate this relationship to nitrate and oxalate content in spinach. Regression analysis was made to test the relationship. Spinach accessions were also divided by breeding method; open-pollinated and F1 hybrids and compared by ANOVA tests. This was also done with the year of release after grouping the cultivars in three; "old cultivars", released before 1970, "medium old cultivars", released between 1970 and 1989, and "new cultivars", released in 1990 or later.

\section{RESULTS}

\section{Spinach versus orache or rocket}

On average, the content of nitrate in rocket was significantly higher than the corresponding values for spinach and orache while no clear difference was found in oxalate content (Table 2, Figure 1). The dry matter was significantly higher for orache than for spinach and rocket.

\section{Nitrate - oxalate relationships}

The heatmap of the descriptors nitrate, oxalate, dry matter and morphological traits of spinach is shown in Figure 2 shows a heat map plot which visualizes the relationship between accessions and descriptors. The plotted grid shows a box for each factor combination which is encoded with a colour depending on the size of the dissimilarity index. Identical colour indicates the same response. The heatmap also plots a dendrogram from a cluster analysis showing the hierarchy of values for both accessions and descriptors. Nitrate and oxalate are very close but not in the same cluster as dry matter content.

\section{Spinach morphology and nitrate/oxalate content}

First, a few characteristics on the examined germplasm collection of spinach: absence of seed spines was most common. Absence of stem anthocyanin was also most common. Accessions with broad ovate leaves were most common, followed by circular leaves. Dark green leaf colour was most common, but a few accessions with yellow-green and grey-green leaves were also observed. Variation in leaf colour intensity was found, as was some variation in leaf blistering, most frequently with medium value. Most of the accessions were monoecious, while variations were found in bolting time. Morphological traits, except monoecious plants and stem anthocyanin colouration, showed no close correlation to nitrate or oxalate content (Figure 2). The Pearson correlation matrix detected no significant correlations between morphological traits and nitrate or oxalate content. Notably, leaf colour and nitrate showed a very low correlation coefficient (r value at 0.02 ) as intensity of green colour and nitrate ( $r$ value at 0.18 ).

\section{Germplasm variation}

Spinach nitrate content varied from $720 \mathrm{mg} \mathrm{NO}_{3} \mathrm{~kg}^{-1}$ fresh weight (NGB2033, cultivar 'Merkur') to $3360 \mathrm{mg} \mathrm{NO}_{3} \mathrm{~kg}^{-1}$

Table 2: Mean value \pm standard deviation of nitrate, oxalate and dry matter content of spinach, orache and rocket

\begin{tabular}{lccc}
\hline Crop & $\begin{array}{c}\text { Nitrate } \\
\left(\mathrm{mg} \mathrm{kg}^{-1} \mathrm{FW}\right)\end{array}$ & $\begin{array}{c}\text { Oxalate } \\
\left(\mathrm{mg} \mathrm{kg}^{-1} \mathrm{FW}\right)\end{array}$ & $\begin{array}{c}\text { Dry matter } \\
(\%)\end{array}$ \\
\hline Spinach $(n=41)$ & $2229 \pm 548$ & $41400 \pm 8474$ & $8.7 \pm 0.5$ \\
Orache $(n=15)$ & $2334 \pm 836$ & $40600 \pm 9372$ & $17.9 \pm 2.2$ \\
Rocket $(n=20)$ & $5672 \pm 603$ & No data & $7.1 \pm 0.5$ \\
$P$ value & $\mathrm{p}<0.001$ & Not significant & $\mathrm{p}<0.001$ \\
\hline
\end{tabular}

$P$ values from ANOVA tests are given 


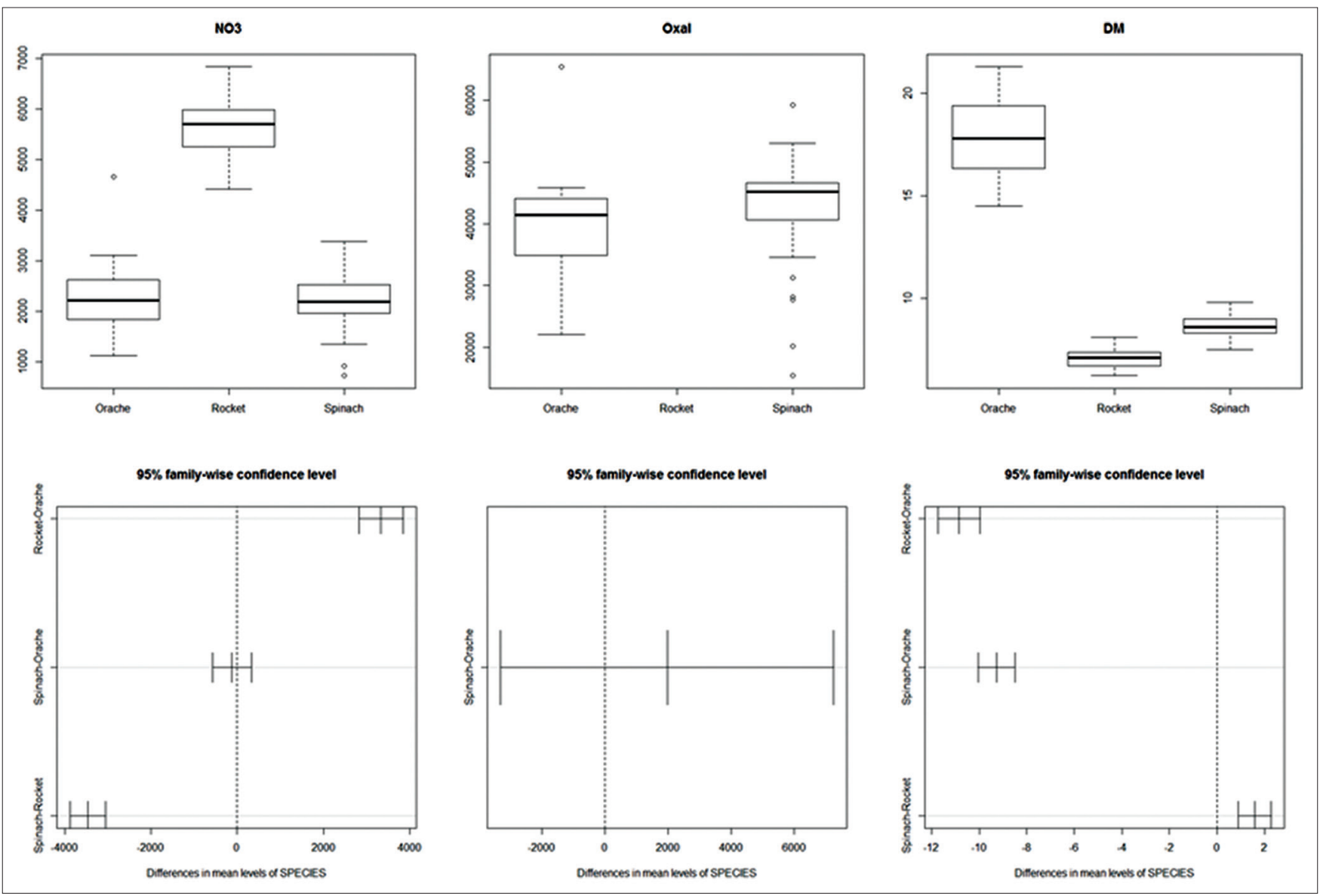

Fig 1. Boxplot of nitrate, oxalate and dry matter content in orache, spinach and rocket (upper three figures) and with Tukey's 'Honest significant difference (lower three figures).

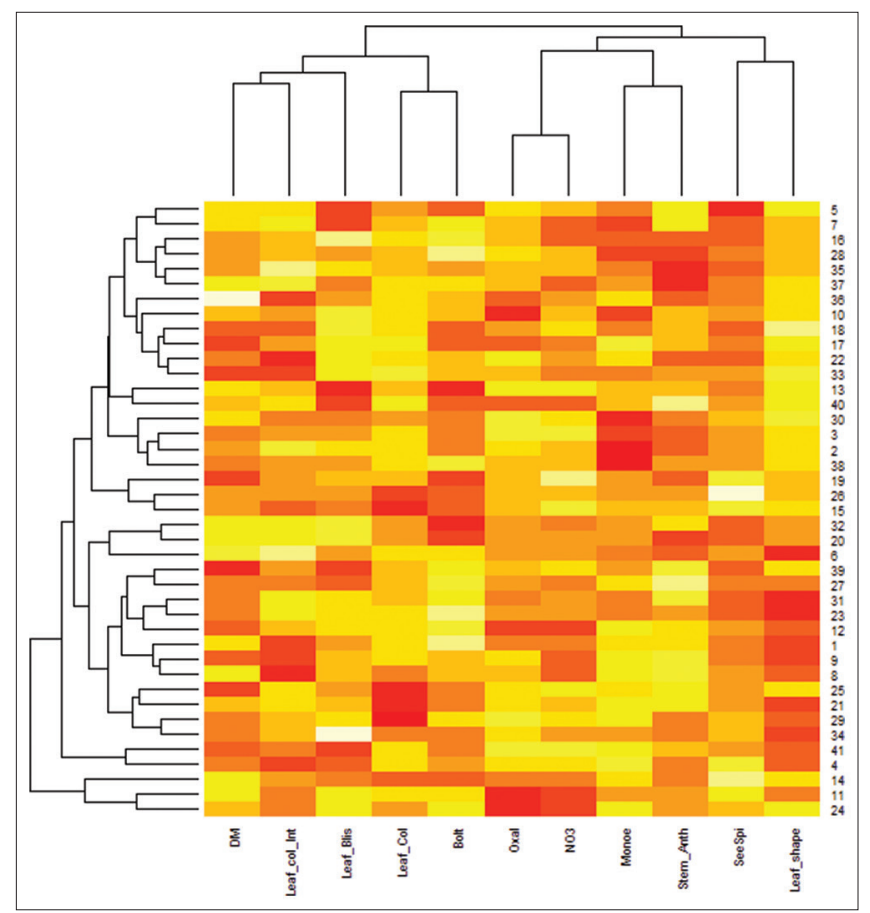

Fig 2. A heatmap cluster analysis of the descriptors and accessions. fresh weight (NGB13180) (Figure 3). The oxalate content varied from 5900 to $53100 \mathrm{mg} \mathrm{kg}^{-1}$ fresh weight, again with NGB2033 'Merkur' being the lowest and NGB2035 the highest. The cultivar 'Merkur', released in 1962, may be important in breeding spinach low in nitrate and oxalate content in the future. Other interesting accessions are NGB2406 'Vikin A Hunderup' from 1942 and the hybrid cultivar NGB18591 'Fornax' (see lower left corner of Figure 3). Orache also showed variation within the collections. One orache accession had low levels of both nitrate and oxalate, with NGB20130 ('Lille Naestad skole'), showing $1120 \mathrm{mg} \mathrm{NO}_{3} \mathrm{~kg}^{-1}$ fresh weight and $22100 \mathrm{mg}$ oxalate $\mathrm{kg}^{-1}$ fresh weight. None of the rocket accessions were found to have low nitrate levels.

Figure 4 illustrates nitrate and oxalate content in spinach related to year of release of spinach varieties. No significant influence of release year was detected for nitrate and oxalate content ( $\mathrm{p}=0.4$ and $\mathrm{p}=0.3$, respectively). Figure 4 illustrate also a tendency to a lower variation among the varieties over time. The ANOVA analysis showed no significant differences in nitrate and oxalate 
between "open-pollinated cultivars" and "F1 hybrids" $(\mathrm{P}=0.5$ and 0.4 , respectively). No significant differences

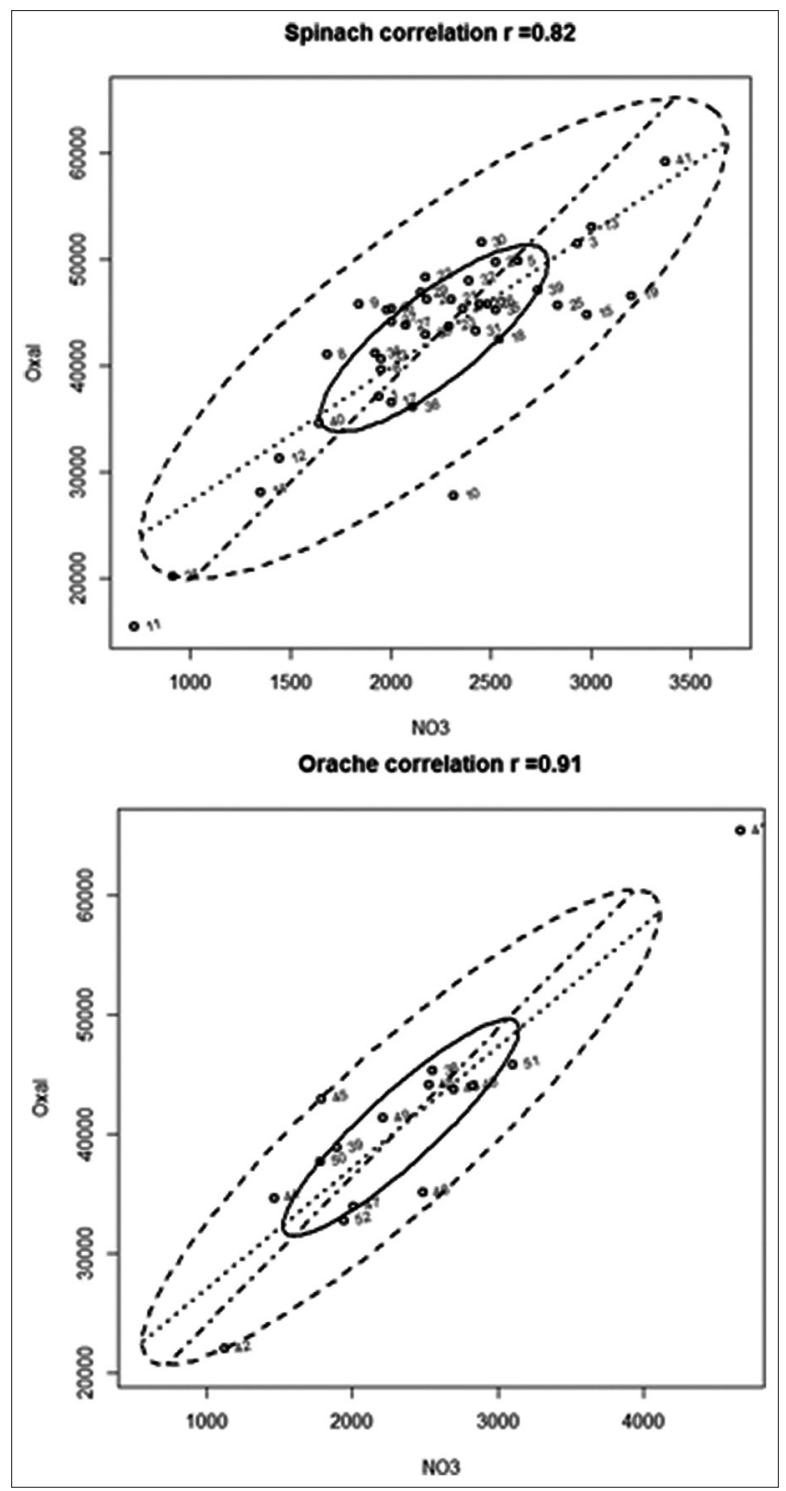

Fig 3. Bivariate plot of nitrate and oxalate content in spinach and orache accessions. in nitrate and oxalate between the groups "old cultivars", "medium old cultivars" and "new cultivars" were found ( $\mathrm{P}=0.7$ and 0.24 , respectively). Almost all F1 hybrids were released after 1990 and belong to the group "new cultivars".

\section{DISCUSSION}

\section{Nitrate and leafy vegetable species}

Our results confirm the high nitrate levels frequently found in rocket (Santamaria et al., 1999). In fact all samples had values in excess of the recommended limits for marketing rocket (Santamaria, 2006). Some of the spinach and orache accession also exceeded the EU limits. The results highlight the importance of fertilizing regimes for such crops (Palaniswamy, 2003; Okazaki et al., 2006). Fertilizing regimes include the balance between $\mathrm{NO}_{3}{ }^{-}$and $\mathrm{NH}_{4}^{+}$, and the supply of nitrogen the last weeks before harvest. Our cultivation method, growing plants in pots with pre-fertilized soil, does not provide sufficient control of nitrogen level. The results furthermore show that orache is of limited value as an alternative to spinach, both as regards nitrate and oxalate accumulation. However, based on dry weight the content is lower.

\section{Nitrate - oxalate relationship}

We have identified a strong positive correlation between the content of nitrate and oxalate in both spinach and orache (Figure 5). Our results are not in line with Kaminishi's and Kita's (2006) who found a moderately negative correlation between nitrate and oxalate content in spinach, but more in line with Koh et al. (2012) that showed a positive correlation, however a slight one, between these components. Elia et al. (1998) demonstrate that oxalate increased with a higher nitrate concentration. Zhang et al. (2005) have shown that increased nitrogen supply increase oxalate content in spinach, but only up to a certain level. Other studies have shown that nitrate can efficiently induce

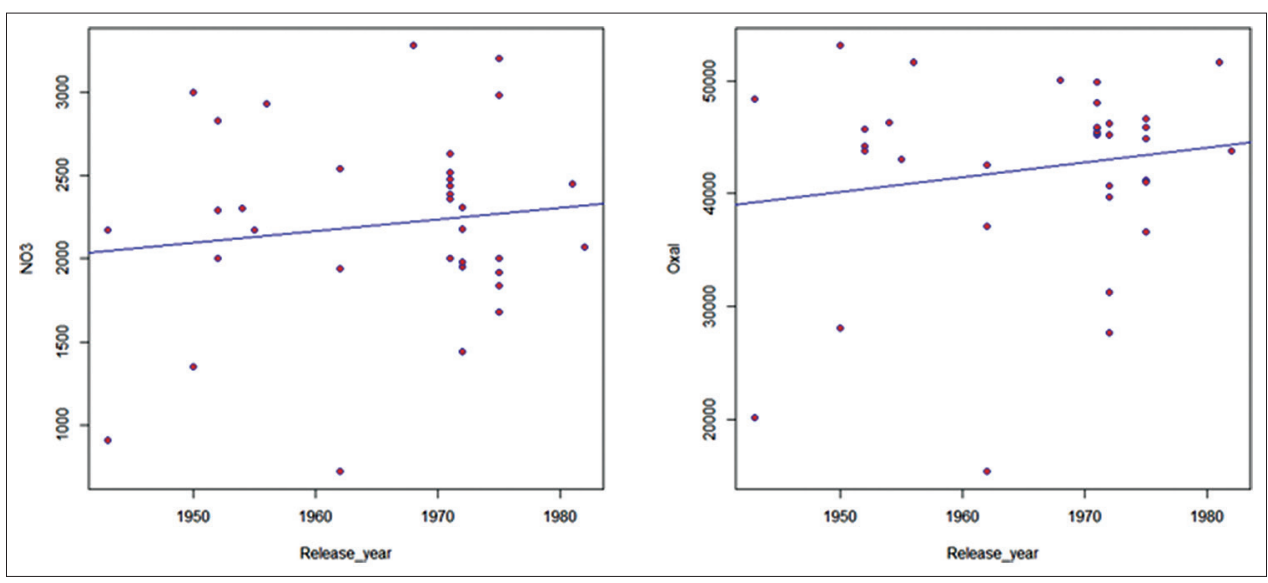

Fig 4. Nitrate (left) and oxalate (right) content in spinach according to release year of the cultivars. 


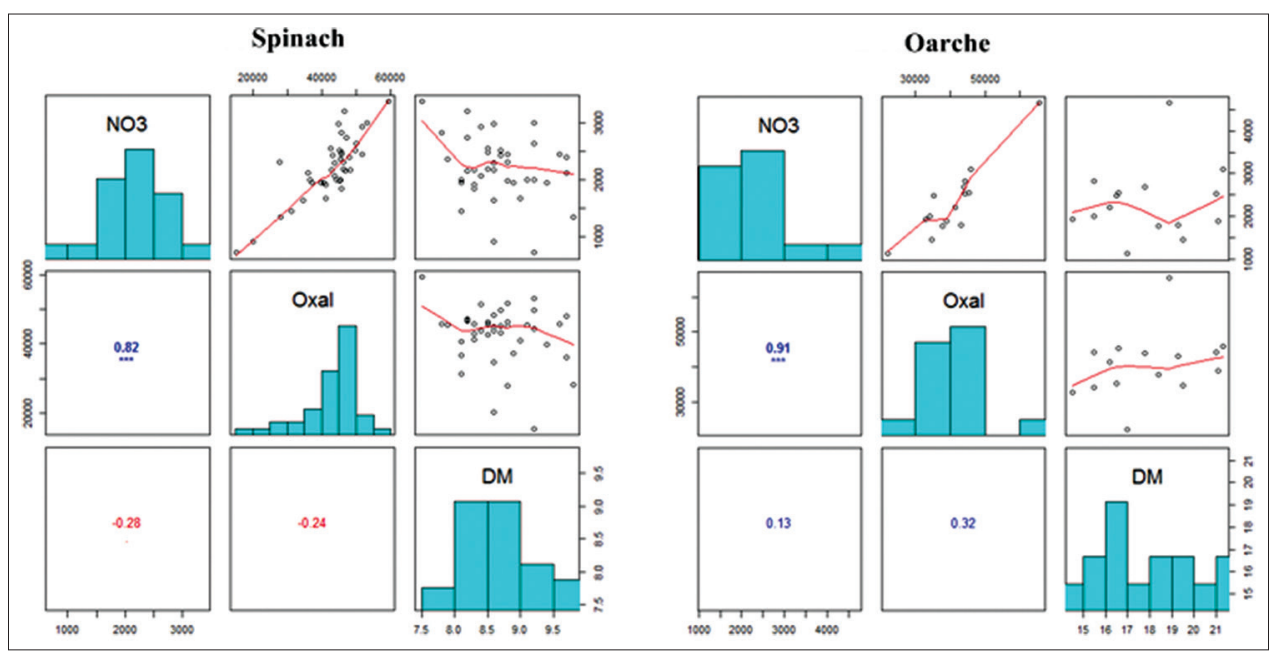

Fig 5. Multipanel display of pairwise relationship between the descriptors of spinach and orache with Person's correlation.

oxalate accumulation in plants, but how it elicits such an effect is not fully understood. Tian et al. (2008) argue that nitrate-induced oxalate accumulation is dependent on the nitrate reductase catalysed nitrate reduction, rather than on nitrate itself.

\section{Potential for breeding of low nitrate and low oxalate spinach}

Our results indicate that breeding, talking in general terms over a 50-year period, has not resulted in any rise or decrease in nitrate and oxalate content in spinach. Although Pavlovic and Stevanovic (1998) found higher nitrate levels in F1 hybrids compared to traditional cultivars, our study does not confirm this relationship. As far as we know low nitrate and oxalate have not been part of the breeding aims of the enterprises behind the examined material. However, breeding of low-nitrate cultivar has been mentioned as one of several methods to reduce nitrate content in spinach in general (Lorenz, 1978; Shen et al., 1986). Maynard and Barker (1973) reported that variation in nitrate concentration may be linked to leaf shape, with savoyleaved varieties having the highest levels and smooth-leaved varieties the lowest. A few years following their initial study in 1973, the same authors said that selection for low nitrate cultivars based on leaf shape had given non-consistent results (Maynard et al., 1976). Groenword (1988) however tested 56 accessions (13 current cultivars, 19 old cultivars and 5 wild) and found no clear effect of cultivar type on nitrate content. Their results were seen as a verification of the prospect that nitrate content reduction through breeding is limited. Willaert et al. (1990) draw the same conclusion after having studied five early spinach cultivars. Noonan and Savage (1999) on the other hand reported that some cultivars of spinach contain 4000-6000 $\mathrm{mg} \mathrm{kg}^{-1}$, while others $7000-9000 \mathrm{mg} \mathrm{kg}^{-1}$. Our study also shows variation among cultivars and a few low-content nitrate cultivars were detected.
The effects of nitrogen forms on oxalate concentrations in plants were reported by several authors, where oxalate content was reduced when ammonium/nitrate ratios in the fertilizers were increased (Takebe and Yoneyama, 1997; Rinallo and Modi, 2002; Zhang et al., 2005). The mechanism of the effects of different nitrogen form on oxalate concentrations in plants is not fully understood, but several processes have been implicated (Reid and Smith, 2001). Regarding oxalate, Murakami et al. (2009) have produced low-content spinach (with one third to one sixth of the oxalate levels compared to control material). This has been done by chemical mutagenesis. One study has shown that cultivars with round leaf blades generally contained less oxalate than those with other leaf shapes (Kawazu et al, 2003), while another study showed that oxalate concentration had little correlation with leaf types (Mou, 2008). Our study agrees with the latter findings. Noonan and Savage (1999) reported that soluble oxalate was the predominant form of oxalate in leaves and petioles and the oxalate concentration in leaves was much higher than that in petioles. Oguchi et al. (1996) reported that selection and breeding of cultivars with a high leaf/petiole ratio is recommended for the production of better quality spinach. We did not measure the leaf/petiole ratio, but we have identified potentially interesting accessions for future breeding of low-oxalate spinach.

\section{CONCLUSION}

In conclusion, this study demonstrates that the levels of nitrate and oxalate are significantly higher across rocket varieties than across spinach and orache varieties, while no clear differences were found between spinach and orache. In general, no differences were found in nitrate and oxalate levels between old and new spinach cultivars or between open-pollinated cultivars and F1-hybrids. A strong positive correlation was found between nitrate and oxalate both in 
spinach and orache and low-nitrate and low-oxalate spinach accessions were identified with potential to be used in spinach breeding.

\section{ACKNOWLEDGEMENTS}

This article is dedicated to Gitte Kjeldsen Bjørn who passed away in June 2015. She was working at the Institute for Agri Technology and Food Innovation in Denmark. She was involved in the present study on leafy vegetables and carried out the morphological characterization. The work was funded by EU grants as part of the project AGRI GEN RES 001: Leafy Vegetables Germplasm, Stimulating Use.

\section{Author contributions}

S. Ø. S. contributed with coordination of the research work and the writing process. F. Y. contributed with statistical analysis and illustrations. J. A. contributed with statistical analysis and practical issues in seed handling and cultivation.

\section{REFERENCES}

Bohn, T., L. Davidsson, T. Walczyk, and R. F. Hurrell. 2004. Fractional magnesium absorption is significantly lower in human subjects from a meal served with an oxalate-rich vegetable, spinach, as compared with a meal served with kale, a vegetable with a low oxalate content. Br. J. Nutr. 91: 601-606.

Chan-Navarrete, R., A. Kawai, O. Dolstra, E. T. L. van Bueren and G. van der Linden. 2014. Genetic diversity for nitrogen use efficiency in spinach (Spinacia oleracea L.) cultivars using the ingestad model on hydroponics. Euphytica. 199: 155-166.

Croitorua, M. D., D. L. Munteanb, I. Fülöpa and A. Modroiua. 2015. Growing patterns to produce 'nitrate-free' lettuce (Lactuca sativa) Food Addit. Contam. Part A. 32: 80-86.

Elia, A., P. Santamaria and F. Serio. 1998. Nitrogen nutrition, yield and quality of spinach. J. Sci. Food Agric. 76: 341-346.

Everitt, B. and T. Hothorn. 2011. An Introduction to Applied Multivariate Analysis with R. Springer, New York/Dordrecht/Heidelberg/ London.

FAOSTAT. 2013. Food and Agriculture Organization of the United Nations. Available from: http://www.faostat3.fao.org/home/ index.html. [Last accessed on 2014 Jun 15].

Ghidurus, M., A. Mitelut, P. Niculita, M. Popa, M. Turtoi and M. Geicu. 2012. Nitrate accumulation in autochthonous varieties of vegetables. J. Environ. Prot. Ecol. 13: 906-912.

Groenword, R. 1988. Nitrate in old and current spinach varieties. Prophyta. 42: 163-165.

IPK. 2015. GBIS/I Genbankinformationssystem des IPK Gatersleben. Available from: http://www.gbis.ipk-gatersleben.de. [Last accessed on $2015 \mathrm{Apr}$ 04].

Kameno, T., T. Kinoshita, M. Kusuhara and M. Noguchi. 1990. The effects of cultural conditions and cultivars on the changes in the contents of components related to the quality of spinach. Bull. Chugoku Nat. Agric. Exp. Stn. 6: 157-177.

Kaminishi, A. and V. Kita. 2006. Seasonal change of nitrate and oxalate concentration in relation to the growth rate of spinach cultivars. Hortsceince. 41: 1589-1595.
Kawazu, Y., M. Okimura, T. Ishii and S. Yui. 2003. Varietal and seasonal differences in oxalate content of spinach. Sci. Hortic. 97: 203-210.

Koh, E., S. Charoenprasert and A. E. Mitchell. 2012. Effect of organic and conventional cropping systems on ascorbic acid, vitamin C, flavonoids, nitrate and oxalate in 27 varieties of spinach (Spinacia oleracea L.). J. Agric. Food Chem. 60: 3144-3150.

Kosma, C., V. Triantafyllidis, A. Papasavvas, G. Salahas and A. Patakas. 2013. Yield and nutritional quality of greenhouse lettuce as affected by shading and cultivation season. Emir J. Food Agric. 25: 974-979.

Krężel, J. and E. Kołota. 2014. Source of nitrogen affects the yield and quality of spinach cultivars grown for autumn harvest. Acta Agric. Scand. B. 64: 583-589.

Lester, G. E, D. J. Makus, D. M. Hodges and J. L. Jifon. 2013. Summer (Subarctic) versus winter (Subtropic) production affects spinach (Spinacia oleracea L.) Leaf bionutrients: Vitamins (C, E, Folate, K1, provitamin A), lutein, phenolics, and antioxidants. J. Agric. Food Chem. 61: 7019-7027.

Lorenz, O.A. 1978. Potential nitrate levels in edible plants. In: Nielsen, D. R. and J. G. Mac Donald (Eds.). Nitrogen in the Environment. Academic Press, New York.

Maynard, D. N. and A. V. Barker. 1973. Variations among spinach cultivars in critical nitrate concentrations. Hortscience. 8: 271.

Maynard, D. N., A. V. Barker, P. L. Minotti and N. H. Peck. 1976. Nitrate accumulation in vegetables. Adv. Agron. 28: 71-118.

Mou, B. Q. 2008. Evaluation of oxalate concentration in the U.S. spinach germplasm collection. Hortscience. 43: 1690-1693.

Murakami, K., M. Edamoto, N. Hata, Y. Itami and M. Masuda. 2009. Low-oxalate spinach mutant induced by chemical mutagenesis. J. Jpn. Soc. Hortic. Sci. 78: 180-184.

Noonan, S. C. and G. P. Savage. 1999. Oxalate content of foods and its effect on humans. Asia Pac. J. Clin. Nutr. 8: 64-74.

Oguchi, Y., W. A. P. Weerakkody, A. Tanaka, S. Nakazawa and T. Ando. 1996. Varietal differences of quality-related compounds in leaves and petioles of spinach grown at two locations. Bull. Hiroshima Prefectural Agric. Res. Cent. 64: 1-9.

Okazaki, K., M. Takebe and T. Karasawa. 2006. Ideal transition pattern of nitrate concentration for improving quality of spinach (Spinacia oleracea L.) and effect of drip fertigation on the sugar and oxalate concentration. Jpn. J. Soil Sci. Plant Nutr. 77: 25-32.

Okutani, I. and N. Sugiyama. 1994. Relationship between oxalate concentration and leaf position in various spinach cultivars. Hortsceince. 29: 1019-1021.

Ota, K. and A. Kagawa. 1996. Effect of nitrogen nutrients on the oxalate content in spinach plants. J. Jpn. Soc. Hortic. Sci. 65: 327-332.

Palaniswamy, U. 2003. Oxalate concentrations in spinach leaves depend on the variety and nitrogen source in hydroponics. Hortscience. 38: 786.

Pavlovic, R. and D. Stevanovic. 1998. The influence of cultivar and fertilization on yield and $\mathrm{NO}_{3}-\mathrm{N}$ accumulation in spinach leaf. Acta Hortic. 456: 269-273.

Proietti, S., S. Moscatello, A. Leccese, G. Colla and A. Battistelli. 2004. The effect of growing spinach (Spinacia oleracea L.) at two light intensities on the amounts of oxalate, ascorbate and nitrate in their leaves. J. Hortic. Sci. Biotechnol. 79: 606-609.

Qiu, W., Z. Wang, C. Huang, B. Chen and R. Yang. 2014. Nitrate accumulation in leafy vegetables and its relationship with water. J. Soil Sci. Plant Nutr. 14: 761-168.

R Core Team. 2014. R: A language and environment for statistical computing. R Foundation for Statistical Computing, Vienna, 
Austria. Available from: http://www.R-project.org/. [Last accessed on 2014 Sep 15].

Reid, R. J. and F. A. Smith. 2001. The cytoplasmic pH stat. In: Rengel, Z (Ed.). Handbook of Plant Growth. Marcel Dekker, Inc., New York. Pp. 49-71.

Rinallo, C. and G. Modi. 2002. Content of oxalate in Actinidia deliciosa plants grown in nutrient solutions with different nitrogen forms. Biol. Plant. 45: 137-139.

Santamaria, P., A. Elia, F. Serio and E. Todaro. 1999. A survey on nitrate and oxalate content in retail fresh vegetables. J. Sci. Food Agric. 79: 1882-1888.

Santamaria, P. 2006. Nitrate in vegetables: Toxicity, content, intake and EC regulation. J. Sci. Food Agric. 86: 10-17.

SESTO. 2015. SESTO Genebank management system. Available from: http://www.sesto.nordgen.org/sesto. [Last accessed on 2015 May 20].

Shen, M. Z., J. G. Li, H. R. Dong, W. F. Du and B. J. Zhai. 1986. Studies on nitrate accumulation and content in local Chinese spinach cultivars. Acta Hortic. Sin. 13: 257-262.

Stagnari, F., V. D. Bitetto and M. Pisante. 2007. M. Effects of N fertilizers and rates on yield, safety and nutrients in processing spinach genotypes. Sci. Hortic. 114: 225-233.

Takebe, M. and T. Yoneyama. 1997. Effect of ammonium-nitrogen supply on oxalate content in spinach grown in hydroponics and fields. In: Ando, T., K. Fujita, T. Mae, H. Matsumoto, S. Mori and
J. Sekiya (Eds.). Plant Nutrition for Sustainable Food Production and Environment. Kluwer Academic Publishers, Tokyo. Pp. 957-958.

Tian, H., L. Jiang, E. Liu, J. Zhang, F. Liu and X. Peng. 2008. Dependence of nitrate-induced oxalate accumulation on nitrate reduction in rice leaves. Physiol. Plant. 133: 180-189.

Wang, H. H., Y. S. Wei and Z. H. Wang. 2006. Relationship between $\mathrm{NO}_{3}-\mathrm{N}$ accumulation and nitrate reductase activity in mesophyll and petiole of different spinach cultivars. Plant Physiol. Commun. 42: $217-220$.

Willaert, G., M. Verloo and R. Sarrazyn. 1990. Influence of cultivar on mineral element contents in spinach. Mededelingen van de Faculteit Landbouwwetenschappen, Rijksuniversiteit Gent 55:83-92 (English text).

Yordanov, N., E. Novakova and S Lubenova. 2001. Consecutive estimation of nitrate and nitrite ions in vegetables and fruits by electron paramagnetic resonance spectrometry. Anal. Chim. Acta. 437: 131-138.

Zeilmaker, M. J., M. I. Bakker, R. Schothorst and W. Slob. 2010. Risk assessment of $\mathrm{N}$-nitrosodimethylamine formed endogenously after fish with vegetable meals. Toxicol. Sci. 116: 323-335.

Zhang, Y., X. Lin, Y. Zhang, S. J. Zheng and S. Du. 2005. Effects of nitrogen levels and nitrate/ammonium ratios on oxalate concentrations of different forms in edible parts of spinach. J. Plant Nutr. 28: 2011-2025. 